\title{
Determination of Canopy's Average SPAD Readings Based on the Analysis of Digital Images
}

\author{
Li Jinwen* \\ Shanghai Academy of Environmental Sciences, Qinzhou Road, Shanghai, China
}

*Corresponding author: Li Jinwen, Engineer, Shanghai Academy of Environmental Sciences, Qinzhou Road, Shanghai, China, Tel: +86-02164085119, Email: coryphium@aliyun.com

Rec date: Mar 26, 2014, Acc date: May 01, 2014, Pub date: May 03, 2014

Copyright: (C) 2014 Jinwen L. This is an open-access article distributed under the terms of the Creative Commons Attribution License, which permits unrestricted use, distribution, and reproduction in any medium, provided the original author and source are credited.

\begin{abstract}
Chlorophyll meter SPAD (Soil Plant Analysis Development) is one of the most popular tools used to monitor the $\mathrm{N}$ Status of rice (Oryza Sativa L.) but its high price limits it from being widely adopted. Digital imaging analysis used to detect nitrogen offers a promising, inexpensive substitute at canopy level. And the present study evaluated rice canopy SPAD readings by analyzing digital images captured with a domestic digital camera. A field experiment was conducted in 2011 using a completely randomized split-plot design, with main-plot treatments of six $\mathrm{N}$ fertilizer application rates and subplot treatments of different plant densities. To remove the image backgrounds, the images were segmented and a dark green color index (DGCl). The index, which is derived from values of hue, saturation, and brightness (HSB), was used to assess the greenness of the rice canopy. The DGCl was significantly correlated with average SPAD readings rice canopy at each growth stage, but the regression lines were different from each other. This might be caused by different lighting conditions, which lead us to conclude a calibration is indispensable when using a digital camera for the diagnosis of a plant's nitrogen status.
\end{abstract}

Keywords: Chlorophyll meter; Paddy field; Machine vision; Rice

\section{Introduction}

A rising concern about the widespread use of $\mathrm{N}$ fertilization has motivated researchers to take a closer look at how to precisely diagnosis a plant's $\mathrm{N}$ status. The chlorophyll (Chl) content of plant leaves is closely related to a leaf's $\mathrm{N}$ content because the photosynthetic apparatus accounts for more than half of a leaf's $\mathrm{N}$ content [1]. In the past few decades, a series of sensor-based devices have been developed to determine a plant's $\mathrm{N}$ status in situ by estimating a leaf s Chl content. These sensors measure the transmittance of light through a leaf's tissues at two wavelengths (Chl meters such as SPAD, CCM, etc.), light reflected by the leaf surface (Greenseek, Yara N-Sensor, etc.) $[2,3]$, or the chl fluorescence emitted by the leaf [4]. Among these techniques, the SPAD chlorophyll meter has become the most used tool and top dressed doses of $\mathrm{N}$ have often been adjusted according to this meter's readings [5]. However, it has been found that a leaf's position may affect the result of these meter measurements [6], and a large number of measurements could be required to ensure accuracy. Additionally, these types of meters were further problematic because of their cost ( $\$ 1,500$ per meter), which leads to most farmers being unwilling to use them.

The canopies of crops treated with different $\mathrm{N}$ application levels reveals different reflectance spectra in visible and infra-red regions (Figure 1). Domestic digital cameras measure the intensity of reflectance in the red $(\mathrm{R})$, green $(\mathrm{G})$ and blue (B) bands, and thus provide an inexpensive alternative method for measuring a crop's $\mathrm{N}$ status. Gitelson et al. [7] suggested that the intensity of green and red reflectance could be used to as an alternative to red and infrared reflectance to measure canopy properties.

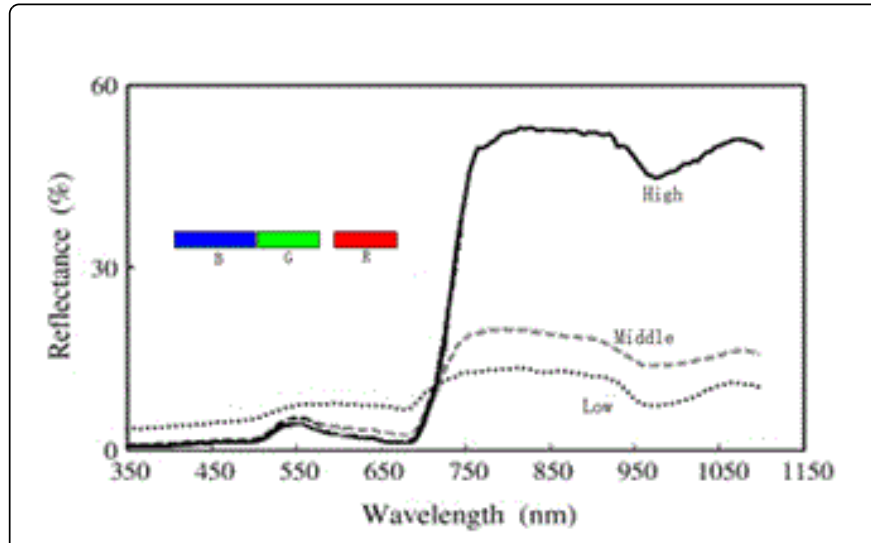

Figure 1: Typical reflectance spectra of crop under low, middle and high $\mathrm{N}$ application levels and approximate widths of the blue, green and red bands of domestic digital cameras.

When the digital images were captured in controllable and constant light environment, there could precisely predict SPAD readings [8]. Nevertheless, the image values of R, G and B for a Lambertian surface are dependent on the light resource, surface reflectance, and the camera sensitivity:

$$
\rho_{k}=\int_{\omega} E(\lambda) * R(\lambda) * S_{k}(\lambda) d \lambda(1)
$$

Where $R \omega$ is the visible spectrum of $R, G, B, E(\lambda)$ is spectral energy distribution, $R(\lambda)$ is surface reflectance, and $S \kappa(\lambda)$ is sensitivity function of camera [9]. The camera's response to light, as well as the spectral composition of the light source, has significant effect on the 
observed canopy reflections and the R, G, and B values. Therefore, when digital cameras are used outdoors for the diagnosis of a plant's $\mathrm{N}$ status, cloud positioning and a camera's light response performance could greatly change the R, G, and B values, which affects $E(\lambda)$ and $S \kappa$ $(\lambda)$ respectively. Recently, Rorie et al. [10] use an internal calibration disk with a known surface reflectance as a reference for correcting the differences found in a camera's light sensitivity and crop's lighting conditions. Li et al. [11] and Wang et al. [12] used canopy cover (CC), calculated by digital images using an image analysis program, was highly correlated with growth and $\mathrm{N}$ nutrition parameters such as leaf area index LAI, shoot dry weight, and shoot $\mathrm{N}$ accumulation. Lee et al. [13] also found that digital camera could be employed for characterizing the growth and $\mathrm{N}$ nutrition status of rice.

The objective of the present paper was to use a real-time method for determining the chlorophyll content of paddy rice grown in a field by evaluating the leaf color image captured with a domestic digital camera. This paper also sought to determine the relationship between a leaf image analysis and a canopy's average SPAD chlorophyll meter readings. The feasibility of using a digital camera as a SPAD substitute was also discussed.

\section{Materials and Methods}

\section{Field experiment}

A 2011 field experiment was conducted with a completely randomized split plot design in Liantang Town, Qingpu district of Shanghai, China $\left(121^{\circ} 00^{\prime} \mathrm{N}, 30^{\circ} 58^{\prime} \mathrm{E}, 3 \mathrm{~m} \mathrm{ASL}\right)$, Seedlings of rice $(O$. sativa L.) cvar Xiushui 28 with five fully expanded leaves were transplanted into plots $(4 \times 5 \mathrm{~m})$ on 28 June. Treatments were arranged in a completely randomized split-plot design with three replications. The main plot treatments were $\mathrm{N}$ application rates of 0 , $75,150,225,300$ and $375 \mathrm{~kg} / \mathrm{ha}$ (pure nitrogen), with sub-plot treatments being two hill densities of $200 \times 150 \mathrm{~mm}$ and $200 \times 100$ $\mathrm{mm}$. Superphosphate $(225 \mathrm{~kg} / \mathrm{ha})$ and potassium chloride $(75 \mathrm{~kg} / \mathrm{ha})$ were incorporated into each plot on the day of transplanting and another $75 \mathrm{~kg}$ potassium chloride/ha was top-dressed 40 days after transplanting (DAT). Each rate of $\mathrm{N}$ was applied in four doses at the following rice growing stages: $0 \cdot 2$ of the $\mathrm{N}$ dose on 3 July (plant reviving), 0.3 on 10 July (tillering), and 0.3 on 6 August (panicle initiation) and the final 0.2 of the $\mathrm{N}$ dose on 30 August (grain filling). The paddy field had loam soil with organic matter content of 40.50 $\mathrm{g} / \mathrm{kg}$ and total $\mathrm{N}$ of $2.13 \mathrm{~g} / \mathrm{kg}$.

\section{Measurements}

\section{Capture of digital camera image}

A color digital camera (Canon A3300 IS, Japan) with a resolution of 16 million pixels was employed to capture color images of the rice canopy. The camera was mounted at a constant height of $1.6 \mathrm{~m}$ on a tripod resulting in a field of view at the soil surface including $24\left(4^{\star} 6\right)$ hills of rice, with an angle between the lens and ground of $30^{\circ}$. Images were taken with auto-focus, auto-white balance, and an automatic exposure time between 9:00 and 16:00. An illumination photometer (TESTO545, German) was used to record the illumination at the paddy field.

All the captured images were saved in a joint photographic experts group (JPEG) file format. A chlorophyll meter SPAD-502 was used to measure the SPAD readings of rice in the camera's field of vision.
About 50 SPAD readings at the middle point of the uppermost leaves in the camera's view were measured and averaged as the canopy's SPAD readings. Segmentation of image and calculation of color index

To remove the background in the digital image, an Otsu thresholding [14] was used. Instead of thresholding the color images, the segmentation was done on the normalized excess green images [15]:

$$
\mathrm{EXG}=(\mathrm{G}-\mathrm{R}-\mathrm{B}) /(\mathrm{G}+\mathrm{R}+\mathrm{B})(2)
$$

Where EXG is index of excess green.

A dark green color index (DGCI), which is derived from values of hue, saturation, and brightness (HSB) was used to assess the greenness of segmented images [16]. RGB values were converted to HSB values using the following algorithms:

$$
H=\left\{\begin{array}{l}
\left(6+\frac{G-B}{\max (\mathrm{R}, \mathrm{G}, \mathrm{B})-\min (\mathrm{R}, \mathrm{G}, \mathrm{B})}\right) \times 60 \text { if } \mathrm{R}=\max (\mathrm{R}, \mathrm{G}, \mathrm{B}) \\
\left(2+\frac{B-R}{\max (\mathrm{R}, \mathrm{G}, \mathrm{B})-\min (\mathrm{R}, \mathrm{G}, \mathrm{B})}\right) \times 60 \text { if } \mathrm{G}=\max (\mathrm{R}, \mathrm{G}, \mathrm{B}) \\
\left(4+\frac{R-G}{\max (\mathrm{R}, \mathrm{G}, \mathrm{B})-\min (\mathrm{R}, \mathrm{G}, \mathrm{B})}\right) \times 60 \text { if } \mathrm{B}=\max (\mathrm{R}, \mathrm{G}, \mathrm{B})
\end{array}\right.
$$

$\mathrm{S}=[\max (\mathrm{R}, \mathrm{G} . \mathrm{B})-\min (\mathrm{R}, \mathrm{G}, \mathrm{B}))] / \max (\mathrm{R}, \mathrm{G}, \mathrm{B}),(4)$

$\mathrm{V}=\max (\mathrm{R}, \mathrm{G}, \mathrm{B})(5)$

$$
\mathrm{DGCI}=[(\mathrm{H}-60) / 60+(1-\mathrm{S})+(1-\mathrm{V})] / 3(6)
$$

\section{Data analysis}

Simple regressions of DGCI values on SPAD readings were obtained. Intercepts and slopes of regression lines at different growth stages were compared using the mixed model procedures of SAS 9.2.

\section{Results and Discussion}

Otsu thresholding method could effectively remove the soil from the rice canopy, while most rice leaves were kept in the digital image (Figure 2). The ambient lighting condition greatly affected the digital image's R, G, and B values, which could be explained by formula 1 . The R, G, B histograms of the rice canopy digital images captured without and with clouds were significantly different (Figure 3). Therefore, to eliminate the effects of variation in solar radiation on DGCI, in the present study the images taken when it was cloudy were excluded. Generally, when cloudless, the illumination in the field ranged from 80000-100000 luxunit of illuminance).
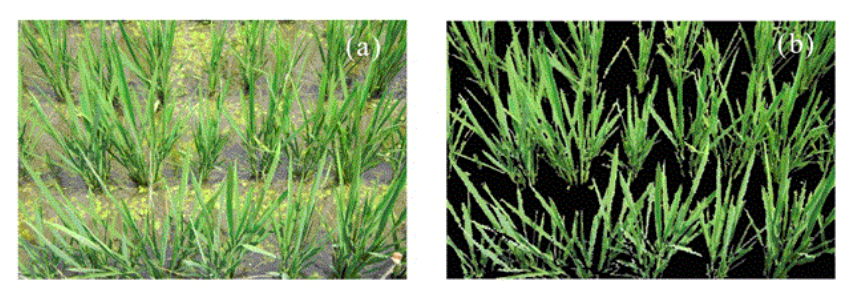

Figure 2: The segmentation of digital image by Otsu's method.

The DGCI values were significantly correlated to the SPAD readings $(\mathrm{P}<0.01$, Figure 4 and Table 1$)$. However, the slopes or intercepts of the regression lines were different from each other. More specifically, at different times, the DGCI readings were not comparable 
when it was used as an indicator of an SPAD reading. Many factors like cloud cover and the digital camera's light sensitivity affected the digital-image-based index's estimate of rice canopy SPAD readings.

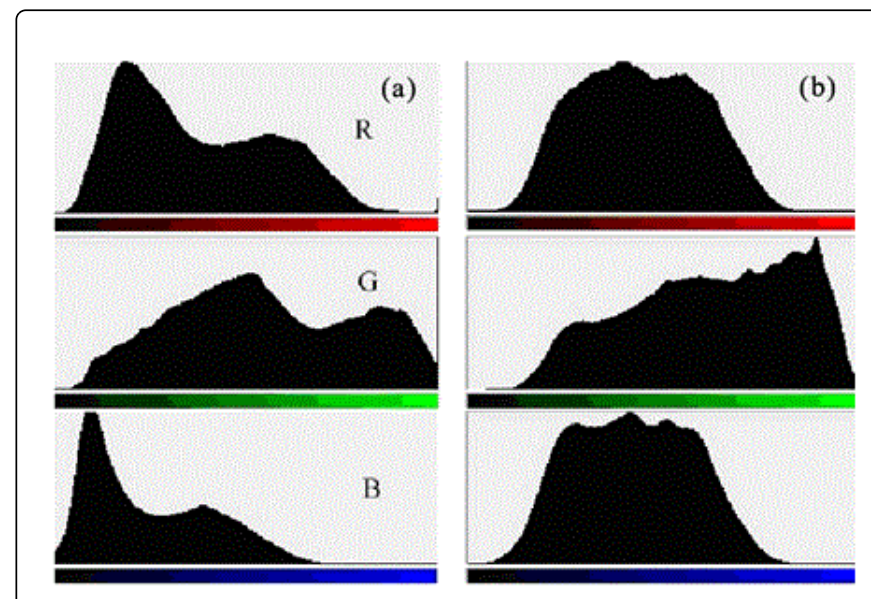

Figure 3: The R, G, B histograms of rice canopy digital images captured without (A) and with clouds in sky.

The correction of the index with a standard calibration disk is indispensable when a digital camera is being used to diagnosis a crop's nitrogen status. One instance of this calibration occurred when farmer's took digital images of corn leaves alongside calibration disks, which then served as internal standards in a two-point regression of actual DGCI values [17].

\begin{tabular}{|l|l|l|l|}
\hline & slope & intercept & $\mathbf{R}^{2}$ (adjusted) \\
\hline DAT28 & $0.0070^{\mathrm{a}}$ & $0.1280^{\mathrm{a}}$ & $0.702^{* *}$ \\
\hline DAT37 & $0.0150^{\mathrm{b}}$ & $-0.1850^{\mathrm{b}}$ & $0.730^{* *}$ \\
\hline DAT48 & $0.0125^{\mathrm{b}}$ & $-0.0452^{\mathrm{c}}$ & $0.482^{* *}$ \\
\hline DAT51 & $0.0883^{\mathrm{c}}$ & $0.0081^{\mathrm{d}}$ & $0.588^{* *}$ \\
\hline
\end{tabular}

Table 1: Slopes and intercepts of linear regression between DGCI (dark green color index) values and canopy SPAD readings measured at day after transplant 28, 37, 48 and 51.

** $\mathrm{P}<0.01 ; \mathrm{a}, \mathrm{b}, \mathrm{c}, \mathrm{d}$ : Significant difference at $\mathrm{P}<0.05$ between the simple regressions formula followed by different letters.

Additionally, it is important that attempts be made to standardize a field's ambient lighting condition, because a crop's solar angle and cloudiness are likely to change a digital image's R, G, and B values (Figure 3). The digital images should be captured on a cloudless day, since on cloudy days the thickness variation of the clouds greatly changes the spectral composition of the solar radiation, which can significantly alter the DGCI values.

\section{Conclusion}

Domestic camera could be used to substitute SPAD for plant N status at canopy level, and it is a promising remote sensing tool for mapping crop $\mathrm{N}$ status at large scale. In the next study, the authors will use unmanned aerial vehicle to capture remote digital images of crops at field level.
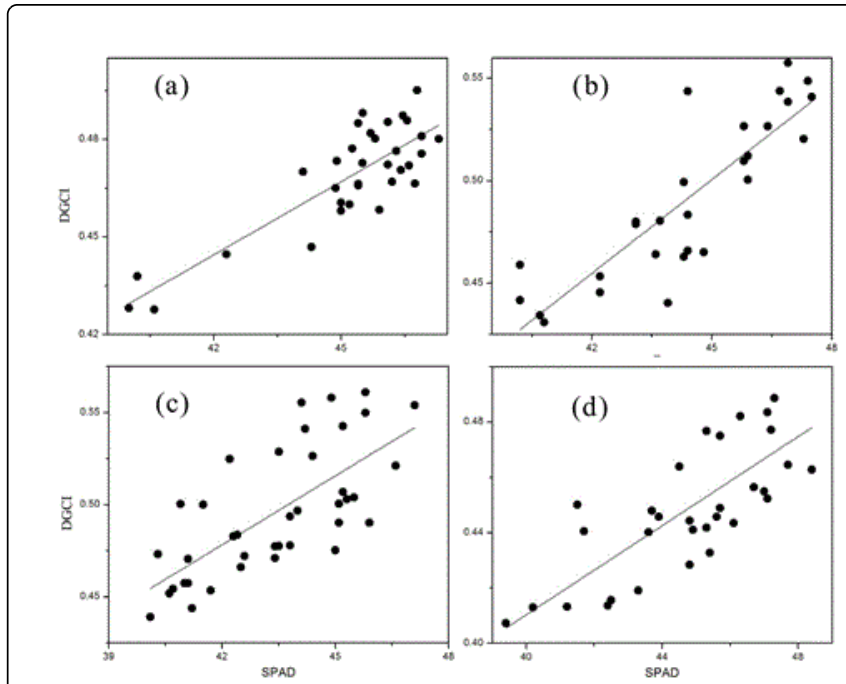

Figure 4: Linear regressions of DGCI (dark green color index) on rice canopy SPAD readings at day after transplant 28(a), 37(b), $48(\mathrm{c})$ and $51(\mathrm{~d})$.

Nevertheless, the images should be captured when it is cloudless, and calibration by standard color disk was indispensable because both different lighting conditions in field and different camera's response to light greatly affected the indices calculated by digital images.

\section{References}

1. Evans JR (1983) Nitrogen and photosynthesis in the flag leaf of wheat (Triticum aestivum L.). Plant physiology 72: 297-302.

2. Berntsen J, Thomsen A, Schelde K, Hansen OM, Knudsen L, et al. (2006) Algorithms for sensor-based redistribution of nitrogen fertilizer in winter wheat. Precision Agriculture 7: 65-83.

3. Samborski SM, Tremblay N, Fallon E (2009) Strategies to make use of plant sensors-based diagnostic information for nitrogen recommendations Agronomy Journal, 101: 800-816.

4. Tremblay N, Wang Z, Cerovic ZG (2012) Sensing crop nitrogen status with fluorescence indicators. A review. Agronomy for sustainable development 32: 451-464.

5. Huang J, He F, Cui K, Bureshb RJ, Xu B, et al. (2008) Determination of optimal nitrogen rate for rice varieties using a chlorophyll meter. Field Crops Research 105: 70-80.

6. Jinwen L, Jingping Y, Pinpin F, Junlan S, Dongsheng L, et al. (2009) Responses of rice leaf thickness, SPAD readings and chlorophyll $\mathrm{a} / \mathrm{b}$ ratios to different nitrogen supply rates in paddy field. Field Crops Research 114: 426-432.

7. Gitelsona AA, Kaufmanb YJ, Stark R, Rundquista D (2002) Novel algorithms for remote estimation of vegetation fraction. Remote Sensing of Environment 80: 76-87.

8. Gupta SD, Ibaraki Y, Pattanayak AK (2013) Development of a digital image analysis method for real-time estimation of chlorophyll content in micropropagated potato plants. Plant biotechnology reports 7: 91-97.

9. Van De Weijer J, Gevers T, Gijsenij A (2007) Edge-based color constancy. Image Processing, IEEE Transactions on 16: 2207-2214.

10. Rorie RL, Purcell LC, Karcherb DE, Kinga CA (2011) The assessment of leaf nitrogen in corn from digital images. Crop Science 51: 2174-2180.

11. Li Y, Chena D, Walkerb CN, Angusc JF (2010) Estimating the nitrogen status of crops using a digital camera. Field Crops Research 118: 221-227. 
Citation: Jinwen L (2014) Determination of Canopy's Average SPAD Readings Based on the Analysis of Digital Images. Agrotechnol 3: 121. doi: $10.4172 / 2168-9881.1000121$

Page 4 of 4

12. Wang Y, Wang D, Zhang G, Wang J (2013) Estimating nitrogen status of rice using the image segmentation of GR thresholding method. Field Crops Research 149: 33-39.

13. Lee KJ, Lee BW (2013) Estimation of rice growth and nitrogen nutrition status using color digital camera image analysis. European Journal of Agronomy 48: 57-65.

14. Otsu N (1979) A threshold selection method from gray-level histogram IEEE Trans. Systems Man Cybern 9: 62-66.
15. Meyer GE, Mehta T, Kocher MF, Mortensen DA, Samal A (1998) Textural imaging and discriminant analysis for distinguishing weeds for spot spraying. Transactions of the ASAE 41: 1189-1197.

16. Karcher DE, Richardson MD (2003) Quantifying turf grass color using digital image analysis. Crop Science 43: 943-951.

17. Rorie RL, Purcell LC, Mozaffari M, Karcher DE, King CA ( 2011) Association of "greenness" in corn with yield and leaf nitrogen concentration. Agronomy Journal 103: 529-535. 